\title{
Novos Rumos da Pesquisa em Plásticos Tenacificados - A Experiência Britânica
}

Tradicionalmente a Inglaterra sempre foi conhecida pelos renomados cientistas que contribuíram significativamente para a compreensão de muitos fenômenos da natureza. As leis de Sir Isaac Newton, a teoria da evolução segundo Darwin e as pesquisas de Cavendish tornaram-se universalmente conhecidas e aceitas. Enquanto os EUA conseguiram grandes avanços tecnológicos na ciência aplicada, na Inglaterra a ciência básica recebeu sempre uma maior atenção. Na área de polímeros é de grande importância tecnológica a compreensão dos mecanismos de tenacificação em plásticos modificados com borracha. Em conseqüência, além do enfoque científico, a tenacificação de polímeros esteve também sempre voltada para os interesses tecnológicos, atraindo parcerias entre universidades e empresas. $O$ Prof. Bucknall, diretor da Divisão de Materiais Avançados da Cranfield University, na Inglaterra, vem contribuindo há 30 anos para o desenvolvimento desta área do conhecimento. Em 1977 editou o livro "Toughened Plastics", utilizado até hoje como referência na área. Atualmente vem trabalhando no modelamento de fenômenos de cavitação da borracha e microfibrilamento em plásticos tenacificados. Além de suas atividades acadêmicas, o Prof. Bucknall é consultor de inúmeras empresas multinacionais nos EUA e Europa e membro atuante de comissões para a organização de eventos técnico-científicos de projeção internacional. A convite do grupo de polímeros do DEMa/UFSCar, esteve em visita ao Brasil em 1989, tendo contribuído até o momento para a formação de dois Ph.D's no país.

Em novembro deste ano, durante a visita da Profa. Dra Vera Soares (Instituto de Química - UFRJ) à Cranfield University, o Prof. Bucknall concedeu esta entrevista aos leitores da revista Polímeros - Ciência e Tecnologia, falando de sua experiência como pesquisador e dos novos desafios nesta virada de milênio.

Como surgiu o "Advanced Materials Research Group”, da Universidade de Cranfield?

O "Cranfield Institute of Technology", que é como nosso estabelecimento foi chamado até 1993, foi criado em 1946 como um centro de pós-graduação para treinamento de engenheiros para a indústria, o que ainda hoje é um de seus objetivos. Os vários departamentos e escolas que compõem a atual Universidade de Cranfield se originaram da primeira escola, ainda hoje existente, o "College of Aeronautics". A Escola de Administração (School of Management), por exemplo, foi criada para resolver um problema burocrático na época da Segunda Guerra Mundial, qual seja, reduzir os entraves administrativos e conseguir que a Inglaterra produzisse aviões em tempo hábil para repor os que eram derrubados nas batalhas. A formação de um Grupo de Pesquisas em Polímeros dentro do Departamento de Materiais da Escola de Manufatura Industrial e Científica (SIMS) se deu em 1959, formando os primeiros Mestres em Ciências em 1960 e se fortalecendo com a contratação do Professor D.W. Saunders, especialista em Física de Polímeros. Um pouco mais tarde fomos contratados, Mike Darlington (1966) e eu (1967).

Como são estabelecidos os programas de cooperação entre o seu grupo de pesquisa e as empresas?

Podemos dizer que há dois esquemas para o estabelecimento destes programas. $\mathrm{O}$ primeiro seria completamente patrocinado pelas indústrias. Nos contratos que gerencio, por exemplo, uma quantia anual é destinada para se empregar um aluno de pesquisa, pagando-lhe uma bolsa de estudos, anuidade escolar e participação em congressos, e ainda para gastar em bens de consumo. Também firma- 
mos um contrato de sigilo profissional em que a companhia fica com a propriedade intelectual e a garantia de que os trabalhos passem por seu crivo antes de serem publicados. Num segundo esquema, podemos ser parcialmente financiados pela agência do governo (EPSRC Engineering and Physical Science Research Council) sem nenhuma ligação com indústrias, se o plano de pesquisa envolve a aquisição de um novo equipamento. Se alguma indústria quiser participar, deverá contribuir com quantias superiores a 10 mil libras esterlinas, havendo possibilidade de haver um conjunto de indústrias participantes. Aqui o direito de propriedade intelectual vai depender da participação efetiva de cada pessoa para a obtenção do produto patenteável, mas posso acrescentar que a universidade não tem condições de vigiar o pagamento de royalties de patentes, nem de bancar questões judiciais com companhias poderosas. É melhor ser modesta nas exigências e garantir algum retorno, principalmente se a implantação do produto depende de terceiros. Quanto a valores investidos nos programas de pesquisa, podemos dizer que professores de renome do nosso Departamento de Materiais, como o Prof. Hohn Nicholson, conseguem atrair recursos da ordem de meio milhão de libras esterlinas por ano.

\section{Como são escolhidos os tópi- cos de pesquisa para os progra- mas de cooperação e quais são os principais no momento?}

Podemos definir três situações: se um pesquisador tem uma linha de pesquisa já bem estabelecida, basta solicitar dinheiro ao governo ou à indústria. Este é o caso em relação ao modelo de

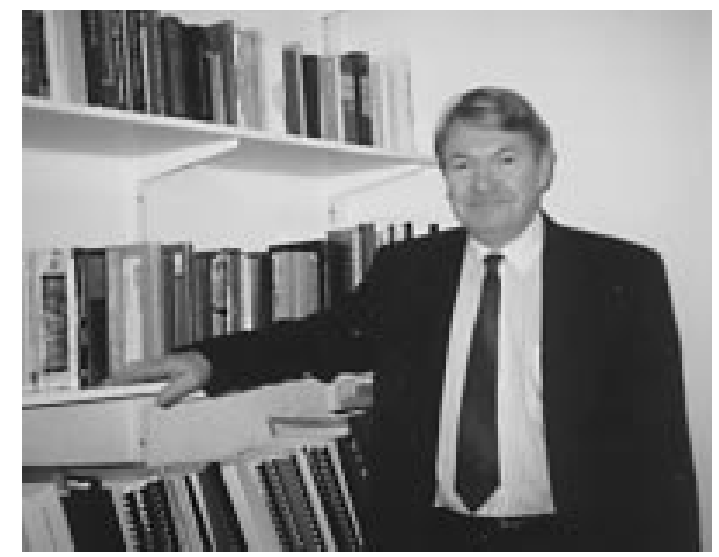

Professor Clive Bucknall

Como diretor do Departamento de Materiais Avançados da School of Industrial and Manufacturing Science (SIMS) da Cranfield University, o professor Clive Bucknall é responsável pelas atividades de

ensino, pesquisa e finanças de um departamento que conta em seu quadro com 6 professors, 2 readers, 2 seniors lecturer e 55 estudantes de pós-graduação e tem entre suas principais pesquisas a tecnologia de revestimentos, cerâmicas, compósitos poliméricos reforçados com fibras e tenacificados, nanotecnologia, eletro-reologia e eletrônica molecular.

As atividades científicas do Prof. Bucknall estão concentradas basicamente no estudo das inter-relações estrutura-propriedades em polímeros, especialmente em plásticos tenacificados com borracha, que geraram a publicação de mais de 100 artigos científicos e a publicação do livro Toughened Plastics (Applied Science Publisher, London, 1977), que se tornou o livro de referência na área. Igualmente importante é o livro Principles of Polymer Engineering (Oxford University Press, 1988 - $2^{a}$ edição 1997), em co-autoria com N.G. McCrum e C. P. Buckley, para alunos de graduação em engenharia de polímeros.

Como os plásticos podem ser tenacificados pela adição de pequenas quantidades de borracha (tipicamente 5 a 20\%), o processo é amplamente utilizado para a produção de formulações de alto impacto de inúmeros produtos comerciais. Os desenvolvimentos recentes incluem a tenacificação de resinas frágeis, utilizando polímeros dúcteis como modificadores de impacto com aplicações na indústria aeroespacial, onde epóxies tenacificadas constituem matrizes de compósitos de alto desempenho.

A pesquisa consiste basicamente no estudo de micromecanismos de tenacificação e das formas de aumentar a tenacidade pelo controle da morfologia. Um dos artigos mais antigos (Bucknall \& Smith 1965) fornece a primeira explicação satisfatória acerca do papel das partículas de borracha na tenacificação de plásticos. Os mais recentes (Lazzeri \& Bucknall 1993, 1995; Bucknall, Karpodinis \& Zhang 1994) proporcionaram uma análise quantitativa mais elaborada acerca do efeito da cavitação da partícula de borracha nos processos de microfibrilação e escoamento na matriz. Estes trabalhos trouxeram novas contribuições para a compreensão do efeito do tamanho médio, distância entre partículas, grau de reticulação da borracha e outros aspectos da tenacificação que até então eram pouco entendidos.

Outras áreas de interesse incluem a tenacificação de resinas utilizando termoplásticos dúcteis e a utilização do monitoramento dielétrico para acompanhamento de mudanças em resinas líquidas durante a cura.

Além do ensino e da pesquisa, o Prof. Bucknall desenvolve uma série de atividades internacionais, como consultor de empresas multinacionais de plásticos de engenharia (GE Plastics, Dow Chemical, Exxon, ICI, American Cyanamid, etc), palestrante convidado em inúmeras conferências (Europa, América, Austrália, China, Japão e Brasil) e membro assessor de conferências internacionais, como o $5^{\text {th }}$ Symposium on Polymer Blends (Maastricht, $12-15$ de maio de 1996) e a $10^{\text {th }}$ International Conference on Deformation, Yeld and Fracture (Churchil College, Cambridge, 7-10 de abril de 1997). 
cavitação quantitativo que estamos desenvolvendo e para o qual conseguimos o apoio financeiro de uma indústria. Numa segunda situação, o financiador se aproxima de você porque o que você faz lhe interessa. No entanto, novas idéias podem ser trazidas pelas indústrias. Esta terceira situação é o caso do nosso departamento de Biotecnologia, que surgiu e se desenvolveu para responder a problemas industriais específicos.

Os principais tópicos desenvolvidos atualmente na área de polímeros em nosso departamento são: - o mecanismo de tenacificação de termoplásticos, em que buscamos um método de detecção quantitativo de vazios (voids) na fase elastomérica, utilizando análise termo-mecânico-dinâmica; - o monitoramento da cura de resinas termorrígidas (envolvendo misturas com elastômeros e termoplásticos ou reforço com fibra de vidro ou de carbono) através da espectroscopia dielétrica dinâmica; - a resistência à fratura de compósitos de fibra contínua; e, ainda, - estudos de peças moldadas por injeção de termoplásticos reforçados por fibras curtas quanto a encolhimento e empenamento (que envolve previsão de orientação e de desempenho mecânico através de métodos computacionais).

Existem programas de cooperação entre seu grupo e outros centros ou institutos de pesquisa na Inglaterra ou em outros países? Como estes programas são estabelecidos?

Atualmente temos um convênio com a universidade alemã Martin-Luther Universitat HallenWittenberg, na pessoa do Prof. G. Michler, e vários acordos de ensino com universidades européias como as de Compiègne e Poitier, na França. Nestes acordos os alunos obtêm um diploma duplo, isto é, de graduação na universidade de origem e de Mestre em Ciências na Universidade de Cranfield. É interessante notar que o modo britânico de ensinar e treinar seus alunos em Engenharia e Ciência é diferente dos outros países europeus, onde o treinamento matemático é esmerado e o trabalho experimental é cuidadosamente planejado. Isso não impede, porém, que esses alunos tão bem treinados fiquem chocados quando recebem um problema real na escola inglesa e verificam que nem sempre tudo dá certo.

Considerando sua larga experiência em pesquisa e como consultor na área de polímeros tenacificados e de compósitos, quais são os desafios tecnológicos e científicos a serem vencidos?

Precisamos entender melhor os aspectos físicos e de engenharia dos materiais, como aconteceu para o desenvolvimento da metalurgia. Em projetos de peças e processamento de materiais (blendas incluídas) já conhecemos alguns princípios gerais, mas muitos fatores-chave ainda nos faltam.
Quais são as perspectivas para uma segunda edição do livro "Toughened Plastics"?

Já comecei a reescrever o livro, mas a área de tenacificação de polímeros está evoluindo muito rapidamente e o acúmulo de tarefas não me permitiu completá-lo. Provavelmente terei que esperar a aposentadoria. Recentemente escrevi um capítulo intitulado "Tenacificação por Elastômeros" para a segunda edição do livro "The Physics of Glassy Polymers" de Howard e Young, e tenho um projeto em andamento de edição do livro "Polymer Blends", com D. Paul.

Que mensagem gostaria de deixar para os jovens cientistas?

Nota-se que a pesquisa está se tornando cada vez mais internacional, que a contribuição por parte de pesquisadores de outros países está aumentando e novos centros de pesquisa em ciência de polímeros vão surgindo em áreas até então sem esta tradição. A contribuição de imigrantes para o desenvolvimento científico sempre foi importante - haja vista aAmérica do início do século - e continua sendo fundamental. Fazer ciência não é só saber colocar a física e a matemática juntas, mas saber pensar cientificamente. Os centros tradicionais teriam esta vocação. Com isto quero dizer que o importante em pesquisa é saber colocar a questão certa. Citamos Colombo, que insistiu na idéia de que, sendo a Terra redonda, seria possível chegar às Índias navegando na direção oeste. 